\title{
PRINCESAS RESSIGNIFICADAS: NUANCES FEMINISTAS EM A BELA E A FERA
}

\author{
Ressignified princesses: feminist nuances on Beauty and the Beast \\ Princesas redefinidas: matices feministas en La Bella y la Bestia
}

\begin{abstract}
Tiago Barcelos Pereira Salgado Pesquisador pelo grupo Campo Comunicacional e suas Interfaces (CCI, PUC Minas/CNPq) tigubarcelos@gmail.com
\end{abstract}

Thayrone Marcos Soares Costa de Carvalho Mestrando em Comunicação (PPGCom PUC Minas), bolsista pela CAPES soaresthayrone@gmail.com

\section{Resumo}

O artigo investiga como a representação social do arquétipo princesa é ressignificada pela Disney no live-action "A Bela e a Fera" (2017) por meio de tentativas de apropriação de aspectos feministas. O estudo se justifica pela investida comercial da Disney na reconstrução da trajetória de personagens femininas, sobretudo conforme a tentativa de remodelação da representação social, dada, em partes, pela quebra do estereótipo feminino dos contos originais, e também devido à grande repercussão que live-actions têm no mercado. O texto recorre aos contos originais, identificando nuances de ruptura do patriarcado masculino, conforme a narrativa apresentada, realizando análise comparativa entre cenas do filme em live-action e do filme em animação. Em conclusão, o arquétipo princesa é parcialmente ressignificado na obra em live-action por meio da apropriação de aspectos feministas.

Palavras-chave: Arquétipo. Princesas Disney. Representação social.

\begin{abstract}
This article aims to investigate how social representation of princess archetype is resignified by Disney in the live-action "Beauty and the Beast" (2017) by appropiation attempts of feminist aspects. This study is justified by Disney's commercial onslaught in the reconstruction of the characters' trajectory, especially as the remodeling of social representation, in parts given by the breaking of the female stereotype of original tales, and also due to the great repercussions that live-actions have on the market. We used original tales, identifying nuances of rupture of the male patriarchy, according to the narrative presented, performing a comparative analysis between scenes from the live-action film and the animated film. It is concluded that the princess archetype is partially reframed in the live-action through the appropriation of feminist aspects.
\end{abstract} Key words: Archetype. Disney Princess. Social representation.

\section{Resumen}

El artículo investiga cómo la representación social del arquetipo de princesa se resignifica en el live-action "La Bella y la Bestia" (2017) mediante los intentos de Disney de apropiación de 
aspectos feministas. Este estudio está justificado por el intento comercial de Disney en la reconstrucción de la trayectoria de los personajes femeninos, especialmente de acuerdo con el intento de remodelación de la representación social, en partes dada por la ruptura del estereotipo femenino de las historias originales, y también debido a la gran repercusión que los live-actions tienen en el mercado. Utilizamos los cuentos originales, identificando matices de la ruptura del patriarcado masculino, de acuerdo con la narrativa presentada, realizando un análisis comparativo entre escenas de la película en live-action y la película animada. Se concluye que el arquetipo de princesa se replantea parcialmente en el live-action a través de la apropiación de aspectos feministas.

Palabras clave: Arquetipo. Princesas Disney. Representación social.

\section{INTRODUÇÃO}

A Disney é a maior companhia de mídia mundial, conforme pesquisa realizada pela Brand Finance em 2018 (DISNEY..., 2018). Fundada em 1923 por Walt Disney e Roy Oliver Disney, a empresa estreou no mercado com animações. O reconhecimento foi alcançado no primeiro longa dos estúdios: uma adaptação do conto "Branca de Neve e os Sete Anões" (1937). De acordo com Silva (2018), a obra foi um sucesso de bilheteria e crítica, com milhões de dólares arrecadados, rendendo à Disney um Oscar especial. ${ }^{1}$ Esse feito inaugurou a trajetória de sucesso da empresa, composta por mais de 96 produções, como "A Bela e a Fera" (1991). Essa animação musical se tornou mais um marco, ao receber cinco indicações ao Oscar, sendo a primeira animação indicada na categoria "Melhor Filme". A produção faturou as estatuetas de "Melhor Trilha Sonora" para Alan Menken, e de "Melhor Canção" para "Beauty and the Beast". Além disso, somou mais de 200 milhões de dólares, valor de arrecadação até o momento inédito para uma animação (a bilheteria hoje se aproximaria dos US\$ 400 milhões).

A narrativa de "A Bela e a Fera" foi revisitada pelos estúdios Disney em 2017 e adaptada fora do gênero animação, assim como "Malévola" (2014), "Cinderela" (2015) e "Aladdin" (2019). A Disney vem expandindo seu universo animado para longas-metragens em live-action — termo utilizado pelo estúdio na denominação de regravações (remakes), com atores e cenários não-animados. Em suma, a Disney passou a recontar os contos de fadas em outro formato, com abordagens e personagens reformuladas de seus contextos originais de época, conferindo-lhes sucesso comercial e consolidação no mercado audiovisual. Isso porque a nova versão de "A Bela e a Fera" conseguiu alcançar o posto de live-action com maior bilheteria dos estúdios Disney e entrar para a lista das dez maiores bilheterias de toda a história do cinema,

\footnotetext{
${ }^{1}$ A estatueta recebida durante a cerimônia de premiação veio acompanhada de sete mini estatuetas do Oscar, referenciando os sete anões da obra.
} 
com faturamento superior a 1 bilhão de dólares até 2017, conforme Bridi (2019). Esse recorde só foi superado em 2019, pela releitura de "O Rei Leão", do mesmo estúdio.

O filme "A Bela e a Fera" (2017), produção live-action, retorna com destaque ao pódio entre as maiores produções cinematográficas, retomando o sucesso da versão animada (com ainda mais êxito, se comparados os lucros gerados), ao atualizar o enredo e as questões da trama, que são revistas e adaptadas para o contexto do século XXI. Na trama, Emma Watson, a jovem atriz e ativista feminista, é a grande estrela, dando vida à personagem Bela. Na versão mais recente, Bela pode e deseja escolher os caminhos que pretende trilhar na vida. Isso se diferencia da época do conto original, em que mulheres não podiam decidir por si mesmas qual seria o seu futuro, condicionado, sobretudo, à escolha paterna.

Na nova versão do conto, para a personagem Bela, importa mais o caráter que a beleza, mais o trabalho árduo e a incessante busca pelo conhecimento que uma vida de luxo e conforto, mais a liberdade de ir e vir que a imposição do casamento por obrigação. A princesa possui motivações condizentes com um cenário contemporâneo de luta feminista, trazendo argumentos relacionados diretamente a um processo de desconstrução do comportamento feminino subjugado ao patriarcado, uma antítese às características principais do arquétipo princesa, antes das novas versões dos contos. ${ }^{2}$ Não se trata, assim, de uma negação histórica do arquétipo, mas de sua atualização e adaptação ao novo cenário temporal no qual a produção live-action se insere.

Em vista disso, este artigo tem como objetivo investigar a ressignificação do arquétipo "princesa" com base na utilização de conceitos feministas ligados ao patriarcado, representação da mulher e ao trabalho no live-action "A Bela e a Fera" (2017), da Disney. A primeira seção traça um paralelo entre a origem dos contos de fadas e o modelo de feminilidade. A segunda aborda o conto original "A Bela e a Fera", suas adaptações literárias, cinematográficas e representações culturais. A terceira busca analisar o discurso e a construção da figura feminina na produção cinematográfica em live-action, apontando diferenças e similaridades entre a obra de 2017 e a animação de conto homônimo, de mesmo nome e da mesma empresa, veiculada em 1991. Por fim, as considerações finais sumarizam o texto e retomam aspectos feministas expressos no live-action analisado.

\footnotetext{
2 É preciso apontar que são muitos os feminismos e que, apesar de não tratarmos do feminismo negro neste trabalho, essa visada é necessária e fundamental para repensar todo o campo de estudos. Algumas das leituras fundamentais são as autoras Angela Davis, Bell Hooks e a brasileira Djamila Ribeiro.
} 


\section{A TRADIÇÃO DOS CONTOS DE FADAS E O MODELO DE FEMINILIDADE}

Os contos de fadas são passados, quer oralmente ou por meio da escrita e da leitura, de geração em geração, permeando a vida e o imaginário das pessoas. Tais histórias narram acontecimentos por meio de metáforas, que representam situações e vivências que transpassam as relações humanas. Para Hueck (2016), há pistas sobre o passado da humanidade escondidas nos contos, em função de tais narrativas serem oriundas da Idade Média e perdurarem até os dias atuais. Tais histórias eram disseminadas oralmente até serem transcritas e, a partir de então, constituírem obras literárias atemporais que impactam diretamente na construção social da humanidade no que tange seus costumes, desejos, ambições, valores, representações e imaginários.

Ao transitar por diversos contextos sócio-histórico-culturais, os contos de fadas, de acordo com Jung (2002), possuem imagens e símbolos que não se limitam ao âmbito individual, sendo culturalmente absorvidos por parte da sociedade, constituindo, assim, representações coletivas. Durkheim citado por Corrêa e Silveira (2014) define as representações como atribuições de valorização do simbólico coletivo, consideradas como princípio elaborador da realidade social. Jung (2000) também determina o inconsciente coletivo como uma camada profunda do inconsciente, que não é formulada apenas com base em experiências pessoais particulares, mas é composta por modos de comportamento denominados cum grano salis, ou seja, modos comuns a todos os indivíduos.

Nesse sentido, as personagens dos contos de fadas podem ser tratadas como referenciais de vida, pois suas personalidades influenciam na formação da identidade do ser, constituindo representações dos seres humanos e da sociedade dentro do inconsciente coletivo ainda que remontem a contextos espaço-temporais distintos dos nossos atuais. Conforme Jung (2002), os conteúdos do inconsciente coletivo são denominados arquétipos. Com base nessa definição, este trabalho se utiliza de tal conceito especificamente para se referir ao modelo de comportamento feminino apresentado pelos contos de fadas em suas adaptações cinematográficas pela Disney. De acordo com Coelho (1991), os arquétipos são derivações dos mitos, porém estão no âmbito do espaço humano e constituem modelos de impulsos e comportamentos humanos presentes no inconsciente coletivo. Conforme Borges e Rodrigues (2018), uma vez que as relações mediadas por imagens se tornaram influências ao consumo, as personagens imaginárias passaram a adquirir significações culturais. Nesse processo, os estúdios Disney também passaram a reforçar modelos e padrões de condutas sociais. Para Correia (2010), o arquétipo "princesa" está presente no processo de socialização humana e 
propõe um modelo de feminilidade. A representação de personagens princesas é apresentada em praticamente todas as obras cinematográficas da empresa e nos produtos que comercializa.

Com base nisso, podemos considerar que as personagens dos filmes da Disney contribuem para a formação da identidade dos públicos, construindo um sentido arquetípico e fantasioso de princesa ao atualizá-lo para a contemporaneidade, tendo em vista a demanda social, cultural e política dos próprios públicos. Logo, a intensa e constante representação de princesas nas obras cinematográficas do estúdio e na indústria do consumo, como a marca "Disney Princesas", ${ }^{3}$ em função da retratação de características muito próprias e da repetição, “cristalizaram um modelo de identidade" (GUATTARI apud CORREIA, 2010, p. 5) feminina no imaginário coletivo: jovem, magra, bela, dócil, heterossexual e vulnerável. Tais adjetivos foram extraídos da descrição do perfil de princesas como Aurora, Bela, Branca de Neve, Cinderela, entre outras, presentes no site Disney Princess (DISNEY, 2019). As qualificações são características comuns às personagens, pois instituem um padrão de ser princesa ao difundir “[...] virtudes, falas, comportamentos e critérios estéticos que caracterizam socialmente a feminilidade” (CORREIA, 2010, p. 9), constituindo, assim, um arquétipo. De acordo com Borges e Rodrigues (2018, p. 116):

[as] personagens se apresentam como pessoas frágeis, solidárias e complacentes, mas fatalmente sofredoras e solitárias, sempre à espera de algo ou alguém que possa transformar os acontecimentos de sua vida. Por conta disto, é que a figura masculina constantemente se transforma em herói, e que como príncipes salvadores as resgatam do sofrimento, associando a felicidade feminina com a presença masculina, que culminará no casamento, selado por um beijo.

No que diz respeito às suas habilidades, as personagens Disney, segundo Borges e Rodrigues (2018), demonstram grande disponibilidade para organização do lar e competência com relação aos afazeres domésticos, como também grande dedicação aos membros da família. Para os autores, as princesas clássicas da Disney se encaixam no modelo feminino das mulheres brancas de classe média alta da época em que os filmes foram desenvolvidos, em que o espaço privado do lar era de exclusiva responsabilidade da mulher: uma obrigação imposta socialmente pelo homem. Sendo assim, o arquétipo princesa se fundamenta em uma representação social dentro de um contexto histórico que estabelecia a dominância da estrutura patriarcal e a necessidade da figura masculina, como era durante a Idade Média, para evidenciar tanto a

\footnotetext{
${ }^{3}$ A partir dos anos 2000, essas personagens foram reunidas na franquia de mídia Disney Princess, com centenas de produtos licenciados pela marca e presença em mais de 90 países, conforme Orenstein (2006).
} 
vulnerabilidade da mulher, que necessita ser "salva" pelo príncipe, quanto a instituição do amor romântico como ideal de felicidade.

Com o live-action "A Bela e a Fera" (2017), a Disney introduz características na trama e na personalidade da princesa Bela que se diferem do arquétipo das princesas clássicas de outras obras: a luta pela liberdade de escolha e a ausência do desejo de encontrar um príncipe/marido. É nesse processo, referente às atitudes femininas, que as princesas da Disney ressurgem em pleno século XXI com traços característicos da atualidade, pois

[a] mulher contemporânea é aquela que, aos poucos, se desvencilha de sua total dependência da figura masculina, conquistando seu próprio espaço na vida pública, desvitalizando-se também do ideal da mulher do lar. Seria a eclosão de um novo papel social feminino a partir da compreensão da mulher sobre o seu próprio ser, do seu próprio corpo e dos seus direitos. (BORGES; RODRIGUES, 2018, p. 119).

O conceito de mulher contemporânea apresentado pelos autores está diretamente ligado às ideologias do movimento feminista. De acordo com a origem da teoria feminista, apresentada por Butler (2003), era necessário o desenvolvimento de uma linguagem capaz de representar a mulher, com o intuito de promover a visibilidade política feminina, perante a "[...] condição cultural difusa na qual a vida das mulheres era mal representada ou simplesmente não representada" (BUTLER, 2003, p. 18). Assim sendo, o discurso feminista decorre da percepção feminina da necessidade da mulher se fazer representar na linguagem e na política.

De acordo com Burckhart (2017), o feminismo surgiu como antítese ao patriarcado, reivindicando direitos civis e políticos às mulheres. Em suas palavras, "[ao] longo dos séculos, entretanto, o feminismo desenvolveu-se no sentido de lutar por novos direitos e causas" (BURCKHART, 2017, p. 222). Para o autor, o feminismo de Butler também desmonta o sujeito histórico do movimento, qual seja, as mulheres, em prol de um feminismo dos corpos abjetos. Isso porque o machismo pode ser considerado como um sistema opressor daqueles que não compartilham do padrão do homem europeu (branco, proprietário, cristão e heterossexual). Para uma melhor compreensão da análise, abordamos no tópico a seguir o enredo da história de "A Bela e a Fera", a origem e as adaptações dessa obra para o cinema, o filme em animação e o live-action, ambos dos estúdios Disney.

\section{O CONTO SOBRE A BELA MULHER QUE DOMA A TERRÍVEL FERA}

O relato do conto "A Bela e a Fera" se tornou célebre nas versões populares produzidas por duas damas francesas em meados do século XVIII. Em praticamente todas as culturas, 
conforme Corso e Corso (2007), há narrativas similares de moças entregues a noivos animais. A versão de Jeanne-Marie Leprince de Beaumont - francesa que trabalhava como governanta na Inglaterra, ensinando meninas sobre a moral de algumas fábulas —, escrita em 1756, é a mais célebre e é a mais parecida com as versões tradicionais dos contos de fadas. Anterior a essa versão, há uma que foi escrita por Madame de Villeneuve, em 1740. Outros contos semelhantes a esse, como destacados por Corso e Corso (2007) são: “A leste do Sol, a Oeste da Lua" e "O Lobo Branco". Outro conto semelhante, porém, às avessas, em que a noiva é enfeitiçada em forma animal, é "A Gata Branca".

A estrutura narrativa do conto "A Bela e a Fera" é relativamente simples. Por necessidade de seu pai, a bela jovem é entregue a um casamento por conveniência, visando a salvar a vida daquele que, a pedido da filha, colhe uma rosa em jardim alheio. Em função do pequeno furto, o dono da propriedade, uma besta condenada a tal condição por uma fada má, condena-lhe à morte, que poderia ser paga com outra vida, se esta lhe fosse voluntariamente dada em casamento. O marido proposto à bela jovem é assustadoramente feio, mas igualmente rico. Ao se deparar com a fera, em sua residência, Bela é surpreendida pela cordialidade e intelectualidade do animal, quando a única expectativa da personagem era ser devorada por ele. Bela ignora que Fera é, na verdade, um lindo príncipe que fora enfeitiçado, até a cena final, em que a besta se transforma em homem. Grande parte da narrativa se centra na convivência da jovem com o monstro, “[...] em que ela vê um amor brotar de dentro das peles de um ser tão pouco atraente" (CORSO; CORSO, 2007, online).

Nos contos de fadas, as dificuldades e os atritos encontrados nas relações entre casais é constante. Conforme Corso e Corso (2007), geralmente é a figura masculina que se torna repulsiva, em função de comportamento animalesco ou indomado. A esse comportamento está associada a feiura, como reforçam os autores. Para Bettelheim (1980), a feiura de Fera pode estar associada à idade avançada da personagem, uma vez que durante o período medieval, moças eram dadas a se casar com aristocratas bem mais velhos que elas. Em "A Bela e a Fera" não é diferente. A personagem Fera, de aparência abominável, encarna atitudes grosseiras, que podem ser justificadas, conforme a narrativa dos contos, por um feitiço ou encantamento a ser vencido ao final pelo amor verdadeiro. Como ressaltam os autores, "[...] esse sentimento terá de se provar como algo maior que a atração física, deverá transcender as aparências" (CORSO; CORSO, 2007, online).

De fato, é possível considerar que o amor de Bela por Fera suplanta as características físicas da primeira personagem. Tais atributos físicos nada mais são do que a expressão interior 
de um comportamento ríspido e autoritário. Em outras palavras, Fera não é apenas fera por fora (o animal), mas também por dentro, o que explica suas ações instintivas e grosseiras. A condição animalesca de Fera, ou sua ferocidade, como seu próprio nome explicita, expressa características atribuídas a um comportamento masculino dominador, autoritário e que subjuga a figura feminina a seus agrados e prazeres, relegando a ela as tarefas domésticas e serviçais. Certamente que tais atitudes estão inscritas espaço-temporalmente no contexto daquela época, ainda que possamos identificar características e atitudes similares no comportamento masculino de hoje.

Conviver com homens bestiais era o destino de muitas mulheres durante a Idade Média na Europa, como destaca Hueck (2016). Elas eram compelidas a se casar com desconhecidos em matrimônios arranjados por familiares. Esses acordos conjugais culminavam no comprometimento das mulheres com verdadeiros "monstros". Na narrativa original, Bela se recusa a casar com o monstro porque o acha repugnante. Outra justificativa encontrada no conto original para essa recusa está em sua juventude e apego ao seio familiar, conforme o seguinte trecho: “[...] Bela, como eu ia dizendo, agradecia aos que queriam desposá-la, mas dizia que era muito jovem e que desejava fazer companhia ao pai por alguns anos.” (BEAUMONT, 2010, p. 98).

A monstruosidade de Fera, expressa em sua condição animal, é usada no conto para reforçar o patriarcado, que se faz presente na relação hierárquica de dominação de Fera sobre Bela. Em função de casamentos arranjados por conveniência, como ressalta Hueck (2016), em vista de interesses econômicos, políticos e sociais - e não por amor ou afinidade - , a mulher estava aprisionada ao homem. Não apenas mulheres da nobreza eram cedidas e presenteadas a homens por seus pais, a partir dos doze anos de idade, para a formação de alianças políticas; mulheres mais pobres também eram trocadas como mercadoria, “[...] já que costumavam vir acompanhadas do dote - um montante de dinheiro que a família da noiva era obrigada a pagar à do noivo" (HUECK, 2016, p. 31).

A ideia de posse ou propriedade dos maridos incidia sobre as mulheres que lhes eram dadas. Esse sentido reforça a suposta missão das esposas à época: servir e obedecer incondicionalmente aos cônjuges. A esse respeito, Hueck (2016) sublinha que as mulheres perdiam seus direitos ao se casarem, como possuir terras ou fazer dívidas. Aos homens, recaía o direito de controlá-las, mesmo que fosse preciso a força física. Um ditado do século XVI dizia exatamente isso: "Um cão, uma nogueira e uma mulher - quanto mais se bate, melhores eles ficam." (HUECK, 2016, p. 31). 
O patriarcado é um sistema ideológico, axiológico e político que preza pela supremacia masculina, pois “[r]eproduz-se mediante um poder simbólico, imperceptível aos olhos dos despercebidos, que opera na subjetividade dos sujeitos” (BURCKHART, 2017, p. 222). Tratase de um mecanismo de poder, mas que passou a ser notório pela contestação realizada por movimentos sociais como o feminismo. É válido ressaltar que essa relação de dominação, historicamente, demorou para ser rebatida também por grandes grupos organizados de mulheres devido à relação "opressor-oprimido". Nessa tensão, segundo Freire (1980), algumas oprimidas, como as mulheres cooptadas pelo patriarcado, em um dado momento de sua experiência existencial, adotam uma atitude de "adesão" ao sistema opressor para serem socialmente beneficiadas sob a ótica de outros processos de dominação de classe.

Apesar das discussões téorico-científicas acerca do movimento feminista contemporâneo terem se estabelecido a partir de 1960, na prática, a denúncia da condição de opressão das mulheres, tendo como principal fator a dominação imposta pelos homens, é historicamente retratada desde a Idade Média, quando, segundo Federici (2017, p. 30), a caça às bruxas " [...] buscou destruir o controle que as mulheres haviam exercido sobre sua função reprodutiva e serviu para preparar o terreno para o desenvolvimento de um regime patriarcal mais opressor". Nas palavras da mesma autora,

[a] definição das mulheres como seres demoníacos e as práticas atrozes e humilhantes a que muitas delas foram submetidas deixaram marcas indeléveis em sua psique coletiva e em seu senso de possibilidades. De todos os pontos de vista - social, econômico, cultural, político —, a caça às bruxas foi um momento decisivo na vida das mulheres; [...] visto que [...] destruiu todo um universo de práticas femininas, de relações coletivas e de sistemas de conhecimento que haviam sido a base do poder das mulheres na Europa pré-capitalista, assim como a condição necessária para sua resistência na luta contra o feudalismo. (FEDERICI, 2017, p. 203).

Como se pode notar, o pensamento da época medieval atribuía ao homem o papel de dono da mulher, podendo fazer com ela o que bem entendesse, sem ser punido por isso. Até os séculos VIII e IX, os homens podiam matar suas esposas por desavenças, sem que esse ato fosse considerado crime (HUECK, 2016). A submissão de Bela à Fera se dava muito mais por medo de que ele a pudesse devorar do que por ela achá-lo feio:

À noite, ao se sentar à mesa, ouviu o barulho que a Fera fazia e não pôde conter um calafrio.

"Bela", disse o monstro, "incomodo se a vejo cear?"

"É o senhor quem reina neste castelo", disse Bela, tremendo.

"Não", respondeu a Fera, "não há aqui outra senhora além de Bela. Caso a esteja aborrecendo, uma palavra sua e vou-me embora. Diga, a senhorita me acha muito feio?" 
"Acho sim", disse Bela. "Não sei mentir. Mas acredito que é muito bom." (BEAUMONT, 2010, p. 109).

É válido destacar ainda o elemento "rosa", que permeia a trama narrativa. Corso e Corso (2007), com base em uma certa liberdade linguística que envolve a palavra latina defloresco, que indica a retirada ou perda das flores, apontam para o sentido alusivo de perder a virgindade. Ao início da trama, Bela solicita ao pai que a presenteie com uma rosa, ou seja, solicita-o que a libere para o casamento (perda da virgindade). Isso poderia explicar o fato de a rosa ter sido proibida ao pai de Bela no jardim do castelo de Fera. A perda da virgindade, nesse sentido, metaforizada pela rosa, deveria ser realizada não pelo pai, mas pelo futuro marido, quem deveria lhe ter entregue a flor. Dito de outra maneira, a rosa não deveria ser oferecida à Bela pelo seu pai, mas pelo seu futuro marido.

Trata-se, no decorrer do conto, de um processo de separação da bela jovem do amor paterno. Se inicialmente a vontade de Bela era ter uma relação assexuada com a Fera, como constata Bettelheim (1980), em virtude de suas características intelectuais e de afeição, ao final do conto podemos sugerir que o desejo amoroso de Bela passa a ser uma relação sexual, sobretudo quando a natureza animalesca de Fera se revela uma natureza humana, afetuosa.

A superação da solidão e cisão do amor paterno é construída ao longo da trama pela demonstração de carinho, cuidado e afeto de Fera que, apesar de sua aparência animalesca, revela-se como dócil e respeitoso. Apesar de pedir Bela em casamento, noite após noite, ela o recusa. $\mathrm{O}$ amor do pai ainda é forte e a impede de receber Fera como seu legítimo amor, pois o amor animal deveria ser rejeitado, tendo em vista a historicidade e repetição de situações matrimoniais forçadas como a de Bela.

Quando se liberta do amor paterno, sem, contudo, desprezá-lo, mas reconhecendo que também pode receber outro amor, Bela passa a ver Fera não mais como animal, mas como ser humano. Ao enxergá-lo desse modo, Bela cria uma condição para que o amor verdadeiro se revele e seja capaz de quebrar o feitiço animalesco atribuído ao belo príncipe escondido sobre pele bestial. A seguir, procede-se à análise comparativa entre a animação de $1991 \mathrm{e}$ o live-action de 2017 da obra "A Bela e a Fera” realizadas pela Disney.

\section{UMA ÓTICA CONTEMPORÂNEA DE UM "CONTO MAIS VELHO QUE O TEMPO"}

Na versão do desenho animado de "A Bela e a Fera", produzida pelos estúdios Disney, em 1991, a trama foi simplificada: a família de Bela se resume apenas a seu excêntrico pai - 
diferentemente do conto original, em que a personagem tinha duas irmãs e três irmãos, com um pai viúvo. Conforme Corso e Corso (2007), a versão animada da Disney apresenta um rival para Fera, aparentemente atraente fisicamente, mas animalesco por dentro. Diferentemente de Fera, seu rival Gaston objetiva se casar com Bela para torná-la uma doméstica a seu serviço aspecto que reforça a tendência patriarcal da Idade Média europeia, como destacam os autores:

Como no caso dos relatos das senhoras do século XVIII, no desenho animado, a figura de Fera se adaptou aos ideais de homem de uma época: de cavalheiro no perfeito domínio das artes do amor cortes, ele se transmutou para um homem delicado e inteligente que uma mulher livre e intelectualizada - a Bela nesse caso amava os livros - espera a seu lado. (CORSO; CORSO, 2007, online).

Por seu turno, a versão em live-action de 2017 do conto "A Bela e a Fera" propôs recriar a versão original animada da Disney com personagens de "carne e osso". A película vale-se da tecnologia 3D o tempo todo, tanto para dar vida às personagens inanimadas (castiçal, relógio, guarda-roupa, entre outros), como para a criação de cenários e efeitos visuais fundamentais (o aspecto da Fera, por exemplo). Apesar disso, a representação imagética das personagens, em sua maioria, é composta pelos próprios atores, diferentemente da animação original.

O live-action conta a história sob a mesma perspectiva da animação. Não há mudanças significativas no roteiro, nos enquadramentos e nos diálogos. Segundo o diretor Bill Condon, em vídeo oficial publicado no canal da Disney no YouTube, não havia a necessidade de recriar uma obra tão aclamada ("EMPOWERED Belle”..., 2017). O diretor pincelou algumas novidades, como novos números musicais e complementos narrativos, sem fugir à fórmula da obra em 2D. A relevância da nova produção, para ele, está na oportunidade de contar a história com fotorrealismo e destacar a personagem Bela "como uma heroína do século XXI". Essa informação é a chave para compreender como Bela rompe com alguns paradigmas de submissão da mulher ao longo da história, assim como o próprio roteiro se encarrega de apresentar e resolver questões relacionadas a um pensamento sexista.

O live-action inicia-se, assim como a animação, narrando os acontecimentos que levaram o príncipe a ser amaldiçoado. Ele é retratado como um homem egoísta e vaidoso, ao oferecer um baile em seu palácio. Aparentemente, trata-se de uma cerimônia para a escolha de uma esposa, pois o salão está inteiramente composto por mulheres que cantam e dançam com ele. De imediato, é possível notar a primeira relação do comportamento masculino com o pensamento patriarcal e sua representação negativa: no mesmo momento em que a personagem está prestes a escolher uma dama para desposar - ato que implicitamente remete a um contexto 
histórico de ausência de liberdade de escolha da mulher, pelos casamentos "arranjados" —, é retratada com características negativas e, devido a uma delas, o egoísmo, é condenado a ter a aparência física daquilo que carrega em sua essência — um monstro selvagem.

Todos os funcionários do palácio também são amaldiçoados e transformados em objetos devido ao caráter duvidoso de seu patrão. Tal acontecimento está diretamente ligado aos conceitos abordados por Butler (2003), onde todos os indivíduos que não se enquadram no padrão dominante masculino estão subjugados ao patriarcado e sofrem consequências negativas por isso.

Bela, interpretada por Emma Watson, surge entoando a mesma canção presente na animação. A música ressalta a beleza de Bela, que contrasta com sua estranheza. A esquisitice, na obra original, remetia ao fato de a protagonista não estar nos moldes das mulheres da aldeia: Bela é uma leitora assídua e não queria se casar, seu desejo era conhecer o mundo. Isso é evidenciado pelas leituras que ela faz de diversos livros, que lhe possibilitam visualizar um futuro longe daquele lugar, expresso com sua corrida pelos campos e o olhar no horizonte. Tais características demonstravam, na obra original em animação, uma representação diferente da princesa Disney em relação às outras personagens da mesma linha. Entretanto, Bela agora não é só "esquisita" por sua incansável dedicação à leitura, mas por ensinar uma outra garota a ler. Essa atitude reflete um comportamento ligado à "sororidade". Tal conceito, de acordo com Beauvoir (1960), diz respeito ao apoio entre mulheres. Uma sociedade patriarcal, segundo a autora, estimula a competitividade entre mulheres e se privilegia disso. Em suas palavras, "[as] mulheres [...] não dizem 'nós'. Os homens dizem 'as mulheres' e elas usam essas palavras para designarem a si mesmas: mas não se põe autenticamente como Sujeito.” (BEAUVOIR, 1960, p. 15). Conforme a autora, a competição atrapalha a organização entre mulheres, o que propicia a dominação masculina.

No mais, no live-action, Bela dá seus próprios passos como inventora. A personagem inventa uma "máquina" de lavar roupa. Tal invenção pode evocar questionamentos acerca da relação de subordinação da mulher como mantenedora do lar, ${ }^{4}$ como foi retratado em filmes animados como "Branca de Neve" (1937), "Cinderela" (1950) e “A Bela Adormecida" (1959). Nessas produções, as personagens-título aparecem, em alguns momentos, dedicando-se a tarefas domésticas. Apesar de buscar um diferencial em relação às representações arquetípicas de "princesa" anteriores, o live-action em questão recai no estereótipo de uma mulher com

\footnotetext{
${ }^{4}$ A autora Bonnie J. Fox (1990) destaca como as propagandas de eletrodomésticos sugerem uma suposta "libertação" feminina, porém, ainda reforçam o lugar do feminino no patriarcado — o lar.
} 
dupla jornada: trabalho remunerado e trabalho doméstico.

Uma das principais teses defendidas por Beauvoir (1960) é a de que o trabalho é uma ferramenta para diminuir a desigualdade entre o homem e a mulher. Entretanto, é válido reafirmar que o feminismo não resolveu todos os problemas das disparidades de gênero. Logo, a carga do trabalho doméstico e a desigualdade salarial ainda são questões muito latentes na sociedade. A esse respeito, Federici (2017) argumenta que a subordinação feminina aos homens no capitalismo foi causada por fatores de opressão, entre eles os processos históricos que estabeleceram o trabalho doméstico como uma atividade obrigatória da mulher, os quais culminaram na não remuneração dessas tarefas. Para a autora, isso não se deu “[ [...] pela natureza improdutiva do trabalho doméstico", mas sim porque a "dominação masculina é baseada no poder que o salário confere aos homens" (FEDERICI, 2017, p. 12).

Segundo o Portal EBC (FREIRE, 2021), em 2019, as mulheres brasileiras dedicaram quase que o dobro de tempo que os homens às tarefas domésticas, sendo 21,4 horas contra 11 horas semanais. Além da dupla jornada, “[...] enquanto o rendimento médio mensal dos homens era de R\$ 2.555,00 [em 2019], o das mulheres era de R\$ 1.985,00” (FREIRE, 2021, online). Conforme pesquisa do IBGE apresentada no referido portal, as mulheres trabalham até dez horas semanais a mais que os homens, recebendo um salário proporcionalmente muito inferior no desempenho das mesmas atividades.

Ainda em relação ao trabalho de Bela, a inventividade atribuída a ela demonstra sua habilidade técnica ao sugerir ferramentas durante a execução das atividades do pai. Em função disso, a personagem usa botas e não sapatilhas - calçado de design delicado utilizado pela jovem na versão animada do conto e que não condiz com as atividades que ela realiza no liveaction (FIG. 1). Ademais, os trajes e a estrutura corporal da personagem não possuem cunho sexual (FIG. 1), o que desmonta o padrão de objetificação e apelo sexual da mulher como característica da feminilidade, de acordo com Beauvoir (1960).
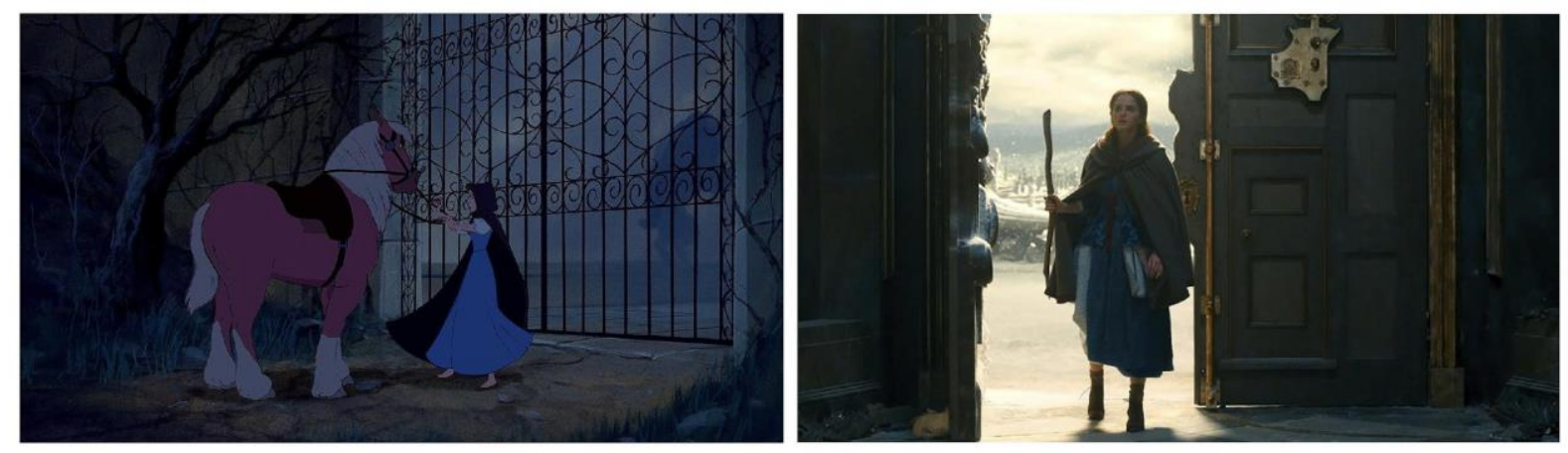

Figura 1. Frames das versões de "A Bela e a Fera".

Fonte: Walt Disney Pictures. 
A questão acerca da liberdade que surge logo no primeiro número musical de ambos os filmes e que move a história, agora aparece com um tom feminista. A frase "É possível ser feliz sem ser livre?" dita por Bela a Fera durante o baile, e que reflete o desagrado da personagem com a vida de clausura que estava levando, relaciona-se com a liberdade feminina. Bela não quer se casar com Gaston, personagem presente em ambas as versões, para cumprir uma norma social, muito menos se dedicar aos cuidados com o possível futuro marido. A ideia de se casar com Gaston é inaceitável para Bela principalmente pela maneira com que a personagem masculina desqualifica a inteligência de Bela, referindo-se ao conhecimento dela como dispensável, pois o que importa para ele é exclusivamente a beleza e a genética, ligados à visão patriarcal da função reprodutora da mulher: Gaston deseja gerar filhos fortes e bonitos com Bela, além de ter uma esposa que se dedique inteiramente aos afazeres domésticos. A

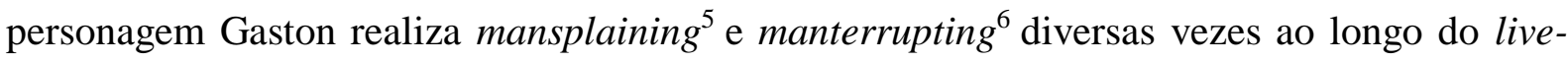
action, ao tentar "ensinar/determinar" o papel de Bela como mulher na sociedade da vila. Estas duas palavras determinam aspectos culturais advindos do sexismo, conforme Butler (2003), e que condizem com situações onde mulheres têm sua inteligência questionada e sua fala interrompida por homens.

Bela é uma mulher destemida. Esse adjetivo é usado por Maurice, pai de Bela, para classificar sua mãe, personagem que não é mencionada na obra animada e, mais a frente, para também classificar a própria filha quando ele lhe diz: "Você é igual sua mãe!”. O adjetivo "destemida" não estava ligado aos demais adjetivos citados anteriormente e que compunham o arquétipo das princesas clássicas da Disney. Assim como a mãe, Bela está disposta a enfrentar desafios. É ela quem vai ao resgate do pai por duas vezes na trama. Ela faz isso montada em um cavalo, ação pouco comum às mulheres no período histórico que o filme procura representar, e uma atitude que simboliza toda a liberdade e autonomia que ela busca na história.

Conforme Beauvoir (1960, p. 9), "ninguém nasce mulher: torna-se mulher." Tal asserção relaciona-se a busca pelo autoconhecimento da personagem Bela no live-action, reforçando que a feminilidade é um espectro amplo, e que a ideia de "fragilidade" não se encaixa nessa personagem feminina e independente que não precisa de um direcionamento

\footnotetext{
5 Termo utilizado para definir situações em que um homem explica algo óbvio a uma mulher, geralmente relacionado a vivências femininas, como se ela não fosse capaz de compreender.

6 Termo utilizado para definir situações em que a fala da mulher é interrompida constantemente por homens, impedindo-a de expressar opiniões e concluir raciocínios.
} 
masculino, importa mais a si mesma e suas escolhas. Além disso, é a própria personagem que toma o lugar de seu pai na cela do castelo, em função de sua condenação por Fera pelo fato de ele ter colhido uma rosa em seu jardim sem permissão. A animação apresenta um acordo entre Fera e Bela, induzido pelo castiçal Lumière, um dos antigos funcionários do palácio que foi amaldiçoado e transformado em objeto animado, que vê na permanência da jovem no castelo uma esperança para a quebra da maldição.

No live-action, Bela assume o lugar de seu pai porque acredita que será capaz de fugir do castelo a partir do momento que Maurice estiver a salvo. Ademais, o live-action introduz também a história da mãe de Bela no enredo: a personagem descobre que a mãe faleceu devido à peste negra que assolou a Europa; para sobreviver, seu pai decidiu abandonar a mulher no leito de morte. Bela tem a oportunidade de tomar decisões diferentes: ela não abandona seu pai quando descobre que ele é levado forçadamente para uma casa de tratamento mental. A personagem Bela tampouco abandona a Fera quando Gaston organiza um ataque coletivo ao castelo. A personagem se prontifica a tentar resgatar ambos os homens do perigo.

A Fera é uma personagem que vivencia uma grande transformação ao longo das duas obras, além do quesito físico, pois passa de príncipe cruel e mesquinho para uma criatura sincera, que demonstra sensibilidade e insegurança. Essas características são antônimas ao modelo patriarcal e autoritário que procura enquadrar os homens no papel de dominância e poder e que, no contexto histórico, estaria de acordo com o fomentado pela sociedade da época. Bela só passa a nutrir sentimentos afetuosos por Fera quando começa a notar a mudança em seu caráter e, principalmente, quando percebe que ele é diferente das pessoas da aldeia. A personagem Fera não só possui o hábito da leitura como também instiga essa paixão por livros em Bela, presenteando-a com a biblioteca do castelo e pedindo para a personagem ler para ele. Não existe estranheza no fato de mulheres lerem, de acordo com Fera, e isso é indício da desconstrução de um pensamento machista na obra. A novidade na história do príncipe amaldiçoado está na exploração de seu passado pelo enredo, visto que, ao longo da trama, o rei, e também o pai da personagem, a partir da morte da esposa, fica responsável pela criação do filho, tornando-se o culpado pela má-criação do príncipe, ao dividir com ele sua maneira de ver a vida. Sendo assim, a figura patriarcal, literalmente, é definida no filme como a responsável pelos problemas morais da personagem Fera.

Presente apenas no live-action, a personagem Ágata a princípio é retratada apenas como uma mulher que pede esmolas. Gaston diz que Ágata é uma mendiga porque esse é o destino de mulheres que não se casam, utilizando isso como argumento para tentar convencer Bela de 
que o matrimônio é fundamental para a mulher. Porém, Ágata se revela, no desenrolar da trama, como a poderosa feiticeira que lançou a maldição no príncipe. Assim, é atribuído à representação da mulher solteira atributos ligados ao poder e à liberdade. Ágata é mais poderosa que todos os personagens masculinos da trama. Ademais, vale ressaltar que Gaston, quando percebe que Bela de fato não irá desposá-lo e que, aparentemente, está apaixonada por Fera, acusa implicitamente a personagem de feitiçaria e envolvimento com magia negra. Devido à figura da feiticeira implicar ideais de empoderamento feminino, foi considerada na Idade Média, num sistema que dava plena autoridade aos homens sobre as mulheres, sinônimo de bruxaria e pecado.

Gaston também, ao longo da trama e, principalmente, durante seu número musical ao lado de LeFou, seu fiel amigo, enfatiza suas características ligadas à virilidade, demonstrando um comportamento masculino dominador e totalmente autoritário. No decorrer da história, a partir da redenção de Fera, quando se envolve afetivamente com Bela e passa a demonstrar seus sentimentos, Gaston assume o papel da Fera. Ele passa a representar todas as características do homem patriarcal e assume integralmente o papel de vilão na trama. Quanto mais feroz Gaston se torna, mais suas características de vilania ficam evidentes e são rejeitadas por Bela.

“Eu não sou uma princesa!". Essa frase é dita por Bela logo que chega ao castelo e é vestida como uma "princesa". No live-action, trajes reais são determinados logo ao início da trama, quando ocorre o baile. Todas as pretendentes do príncipe e membros da corte estão vestidos com perucas brancas e/ou penteados altos, roupas volumosas e maquiagem específica, como mostra a Figura 2. Essas vestes fazem parte da cultura francesa e eram utilizadas pela monarquia. A personagem Bela não adere a esse padrão estético quando chega ao palácio e nem ao final da história, quando, ao lado do príncipe, ocupa uma posição de princesa. Entretanto, essa mudança estética condiz mais com um deslocamento na representação estética da personagem, que dá espaço para uma volta aos moldes já estabelecidos, do que com uma ruptura. Isso porque há evidências de uma reprodução do modelo de feminilidade (CORREIA, 2010) na caracterização da personagem Bela do live-action, posto que ela ainda é uma mulher branca, magra, heterossexual, que utiliza vestidos de acordo com o contexto histórico da obra e que, por fim, ainda desfruta de um relacionamento pautado pelo amor romântico com uma figura masculina dominante. 

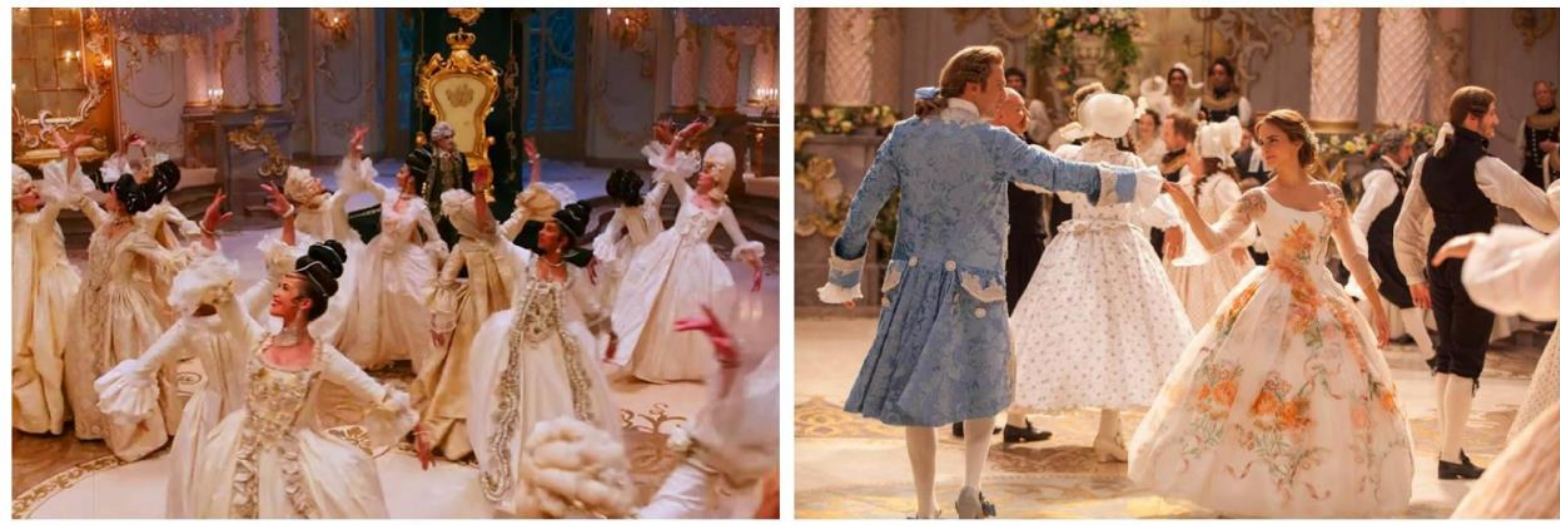

Figura 2. Frames da versão live-action.

Fonte: Walt Disney Pictures.

De acordo com o conceito de um "sujeito oprimido" abordado por Butler (2003), o liveaction também, a princípio, parece desconstruir o pensamento patriarcal ao dar espaço para tramas paralelas com diversidade entre personagens que não se enquadram no padrão normativo citado pela autora (homem, branco, heterossexual, europeu, rico, etc.), como LeFou, possuindo características homossexuais e subentendendo um relacionamento homoafetivo entre ele e um dos moradores da aldeia, que era também capanga de Gaston (FIG. 3). Entretanto, a homossexualidade de LeFou é introduzida na narrativa de maneira cômica.

Essa relação entre homossexualidade, homoafetividade e o humor, em suma, é estabelecida para construir a ideia do Outro, o diferente e, na maioria dos casos, o não digno da existência. Isso porque a matriz heterossexual exige que certos tipos de identidade não possam "existir", ou seja, “[...] aquelas em que o gênero não decorre do sexo e aquelas em que as práticas do desejo não 'decorrem' nem do ‘sexo' nem do 'gênero'.” (BUTLER, 2003, p. 39). Portanto, segundo Butler (2003), as normas de inteligibilidade socialmente instituídas e mantidas como reguladoras da condição de "pessoa" banem corpos que não se caracterizam conforme suas lógicas, os chamados corpos abjetos, e impossibilitam a ressignificação de sua representação, invisibilizando culturalmente, silenciando e excluindo o status de sujeito dessas pessoas. Sendo assim, o live-action ainda apresenta as personagens com características homossexuais em prol do riso, assim como a maioria das produções da indústria audiovisual que retratam o tema. 


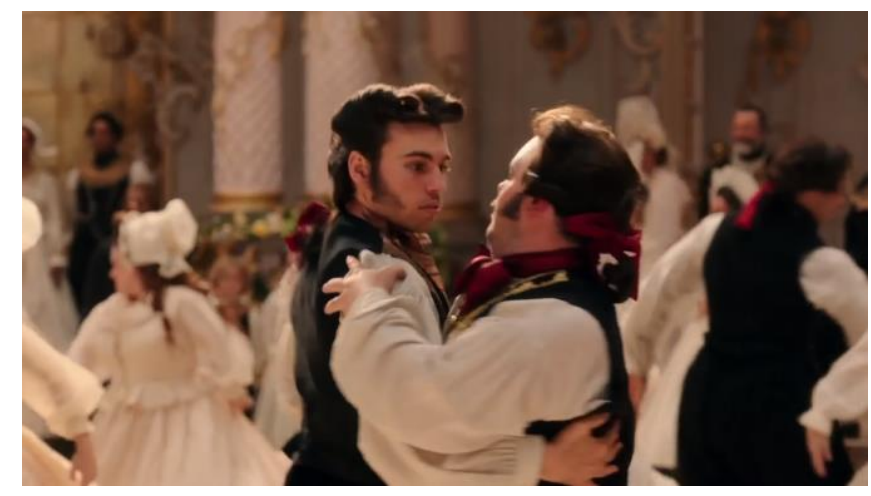

Figura 3. Frame do live-action. Fonte: Walt Disney Pictures.

\section{CONSIDERAÇÕES}

O arquétipo princesa é ressignificado na obra em live-action por meio da apropriação de conceitos próximos às teorias feministas na nova representação da princesa Bela, principalmente pela tentativa de desconstrução do pensamento patriarcal dentro do filme e pelo rompimento desse domínio das figuras masculinas sobre as personagens. No contexto geral da produção de “A Bela e a Fera” em live-action, conseguimos verificar adaptações no roteiro com relação ao filme em animação e que, de fato, existe uma transformação nas habilidades e motivações da protagonista Bela, conforme demanda social, cultural e política dos públicos visando fins comerciais. Em relação a representação dessa personagem na obra em animação, a produção de 2017 a apresenta com maior liberdade feminina quanto à escolha de seus caminhos, um maior desprendimento à obrigação matrimonial, no que diz respeito à sua própria felicidade, e com características físicas atribuídas às princesas pelo arquétipo presente em outros filmes da Disney, em menor evidência. A Bela de Emma Watson é menos doce, menos delicada, utiliza roupas que condizem com seu cotidiano e sua beleza não está moldada por padrões irreais de perfeição.

Com efeito, Bela é apresentada em uma versão mais destemida, que peita de frente o monstro e resume seu espírito ao responder se poderia ser feliz, mesmo presa no castelo: "É possível ser feliz sem ser livre?”. Além disso, a Bela do live-action, em contraste com a Bela da animação, não está sonhando com um príncipe encantado e muito menos está à procura de uma figura masculina para desposar. Ela não deseja tornar-se uma princesa. Bela está mais interessada em descobrir "quem ela é", em desvendar os segredos sobre seu passado e em traçar seu próprio futuro. As diferenças com relação ao conto original são ainda mais pontuadas, visto que a obra em animação de 1991 já demonstrava uma grande mudança na narrativa e foi utilizada como base para o live-action. Contudo, apesar das atitudes de Bela relacionadas ao 
modelo de luta feminina contemporânea, ela ainda assume um conjunto de "características tradicionalmente femininas" construídas culturalmente, conforme Beauvoir (1960), comuns ao arquétipo "princesa" instituído pelas obras anteriores, como beleza, doçura, gentileza, compaixão. Bela se enquadra, ainda, junto às demais personagens do filme, numa instituição de gênero e sexualidade analisados e desconstruídos por Butler (2003) em sua obra feminista.

\section{REFERÊNCIAS}

A Bela e a Fera (Beauty and the Beast). Direção: Gary Trousdale e Kirk Wise. Produção: Don Hahn. Walt Disney Pictures, 1991. 84 min, cor.

A Bela e a Fera (Beauty and the Beast). Direção: Bill Condon. Produção: David Hoberman e Todd Lieberman. Walt Disney Pictures, 2017. 2h09min, cor.

BEAUMONT, J. L. A Bela e a Fera. In: MACHADO, A, M. Contos de fadas: de Perrault, Grimm, Andersen \& outros. p. 97-118.

BEAUVOIR, Simone de. O Segundo Sexo, v.I, II. Tradução Sérgio Milliet. Rio de Janeiro: Nova Fronteira, 1980.

BETTELHEIM, B. A psicanálise dos contos de fadas. Rio de Janeiro: Paz e Terra, 1980.

BORGES, H. P.; RODRIGUES, R. F. A tradição dos contos de fada e a sobrevivência de matrizes culturais femininas nas narrativas cinematográficas infantis. INTERthesis, Florianópolis, v. 15, n. 3, p. 109-127, set./dez. 2018. Disponível em: https://periodicos.ufsc.br/index.php/interthesis/article/view/1807-1384.2018v15n3p109. Acesso em: 15 out. 2019.

BRIDI, N. De 101 Dálmatas a O Rei Leão: as maiores bilheterias dos remakes da Disney. Omelete, online. 14 de agosto de 2019. Cinema. Disponível em: https://www.omelete.com.br/filmes/rei-leao-maiores-bilheterias-remakes-live-actiondisney\#3Acesso em: 20 ago. 2019.

BURCKHART, T. Gênero, Dominação Masculina e Feminismo: por uma Teoria Feminista do Direito. Revista do Departamento de Ciências Jurídicas e Sociais de Unijuí, ano XXVI, n. 47, p. 205-224, jan./jun. 2017.

BUTLER, J. P. Problemas de gênero: feminismo e subversão da identidade. Rio de Janeiro: Civilização Brasileira, 2003.

CHARNEY, L.; SCHWARTZ, V. Introdução. IN: CHARNEY, L.; SCHWARTZ, V. O cinema e a invenção da vida moderna. São Paulo: Cosac Naify, 2004.

COELHO, N. N. O conto de fadas: símbolos - mitos - arquétipos. São Paulo: Ática, 1991.

CORRÊA, L. G; SILVEIRA, F. J. N. Representação. In: FRANÇA, Vera Veiga; 
GUIMARÃES, Bruno; MENDES, André Melo. (Orgs.) Grupo de Pesquisa em Imagem e Sociabilidade (GRIS): trajetória, conceitos e pesquisa em comunicação. Belo Horizonte: Faculdade de Filosofia e Ciências Humanas - PPGCom - UFMG, 2014. p. 208-215.

CORREIA, R. M. O Arquétipo da Princesa na Construção Social da Feminilidade. 2010. 77f. Monografia (Mestrado em Estudo sobre as Mulheres - As mulheres na Sociedade e na Cultura) - FCSH - Faculdade de Ciências Sociais e Humanas - Universidade Nova de Lisboa, Lisboa, 2010.

CORSO, D. L.; CORSO, M. Fadas no divã [recurso eletrônico]: psicanálise nas histórias infantis. Porto Alegre: Artmed, 2007.

DISNEY. Disney Princess. Página inicial, online. Disponível em: http://princess.disney.com. Acesso em 3 ago. 2019.

DISNEY Sparkles as Most Valuable Media Brand of the Year. Brand Finance, online, 2018. Disponível em: https://brandfinance.com/news/disney-sparkles-as-most-valuable-mediabrand-of-the-year. Acesso em: 9 ago. 2019.

"EMPOWERED Belle" Featurette - Disney's Beauty and the Beast. YouTube. 1 de março de 2019. Vídeo (1h29). Publicado por Walt Disney Studios. Disponível em: https://youtu.be/E_yT_icxszM. Acesso em: 12 jul. 2019.

FEDERICI, S. Calibã e a bruxa: mulheres, corpo e acumulação primitiva. São Paulo: Elefante, 2017.

FOX, B. J. Selling the mechanized household: 70 years of ads. Gender \& Society, v. 4, n. 1, p. 25-40, 1990. Disponível em:

https://journals.sagepub.com/doi/10.1177/089124390004001003. Acesso em: 17 ago. 2021.

FREIRE, P. Conscientização: Teoria e prática da libertação: Uma introdução ao pensamento de Paulo Freire. São Paulo: Moraes, 1980.

FREIRE, T. Dupla jornada e salários menores: realidade que ainda afeta mulheres. Agência Brasil, online. 4 de março de 2021. Disponível em:

https://agenciabrasil.ebc.com.br/radioagencia-nacional/economia/audio/2021-03/duplajornada-e-salarios-menores-realidade-que-ainda-afeta-mulheres. Acesso em: 16 ago. 2021.

HUECK, Karin. O Lado Sombrio dos Contos de Fadas. Revista Superinteressante, São Paulo, 367, p. 25-33, nov. 2016.

JUNG, C. G. O homem e seus Símbolos. Rio de Janeiro: Nova Fronteira, 2002.

JUNG, C. G. Os arquétipos e o inconsciente coletivo. Petrópolis: Vozes, 2000.

ORENSTEIN. Peggy. What's Wrong with Cinderella? The New York Times Magazine. 24 de dezembro de 2006. Disponível em:

https://www.nytimes.com/2006/12/24/magazine/24princess.t.html. Acesso em: 3 ago. 2019. 
SILVA, C. C. Qual o desenho animado mais importante da história? Revista

Superinteressante. 2018. Disponível em: https://super.abril.com.br/mundo-estranho/qual-odesenho-animado-mais-importante-da-historia. Acesso em: 13 ago. 2019.

Original recebido em: 15 de maio de 2020

Aceito para publicação em: 28 de setembro de 2021

Tiago Barcelos Pereira Salgado

Pós-doutor em Comunicação pela PUC Minas, com bolsa CAPES.

Doutor e mestre em Comunicação pela UFMG.

Pesquisador pelo Grupo de Pesquisa Campo Comunicacional

e suas Interfaces (PUC Minas/CNPq).

Thayrone Marcos Soares Costa de Carvalho

Mestrando em Comunicação pela PUC Minas, com bolsa CAPES.

Bacharel em Publicidade e Propaganda pela PUC Minas.

\section{@ $\odot \Theta \odot$}

Esta obra está licenciada com uma Licença

Creative Commons Atribuição-NãoComercial-CompartilhaIgual 4.0 Internacional 